\title{
Characteristics of cosmopolitan consumers with a global identification: An exploratory analysis of Japanese consumers
}

\author{
Shinichiro Terasaki ${ }^{1}$ and Christopher Perkins ${ }^{2}$ \\ ${ }^{1}$ Lecturer, School of Humanities and Social Sciences, Faculty of Humanities and Social Sciences, Kochi University, Kochi, Japan \\ ${ }^{2}$ Senior Lecturer, School of Literatures, Languages and Cultures, Faculty of Asian Studies, The University of Edinburgh, \\ Edinburgh, United Kingdom
}

\begin{abstract}
While consumer cosmopolitanism has become a popular topic in international marketing, little is yet known about the way in which people become consumer cosmopolitans in the first place. This study examines reciprocal relationships among antecedents of cosmopolitan consumers with a global identification (CCGI). Through a combination of C-COSMO and Consumer Localism scale, CCGI were extracted from Japanese students as prospective interviewees. Subsequently, interviews were conducted with twenty theoretically sampled CCGI. Grounded theory approach analysis of the qualitative data revealed the following four categories of antecedent characteristics: Influence of immediate family; Personal international social networks; Education; and Personality, and the following three moderators: Kyoiku mama; Reaffirming national identity; and Adaptation stress. Subsequently the relationship between antecedents and moderators is developed as a transition process to becoming a cosmopolitan consumer. We also specify influence of immediate family as a key antecedent in the transition process, and found cosmopolitanism as a situational identity strategy activated in particular contexts.
\end{abstract}

Key words: cosmopolitanism, globalization, acculturation, consumption, grounded theory approach

\section{INTRODUCTION}

Against the backdrop of accelerated globalization, we have since the 1990s witnessed the formation of a new breed of cosmopolitan consumers. These cosmopolitan consumers are open to new ideas and address their needs with products and services regardless of their national traditions and local influences (Cannon, Yoon, McGowan, \& Yaprak, 1994, p. 6). But while consumer cosmopolitanism has become a popular topic in the international marketing literature, little is yet known about how people become consumer cosmopolitans in the first place (Riefler \& Diamantopoulos, 2009; Terasaki, 2016; Zeugner-Roth, Zabkar, \& Diamantopoulos, 2015). The aim of this paper, therefore, is to develop our understanding of this consumer demographic by exploring why and how antecedents link to processes of becoming a cosmopolitan consumer.
According to Cannon and Yaprak (2012), cosmopolitan consumers can be classified into two subcategories: cosmopolitan consumers with a global identification (CCGI), and cosmopolitan consumers with a local identification (CCLI). The former "espouse values of open-mindedness and acceptance of diversity while not identifying with a local culture," while the latter "espouse values of openmindedness and acceptance of diversity while identifying primarily with a local culture" (p. 12). As a first step towards comparative analysis of these two consumer groups in this paper we decided to focus on CCGI.

The research process went as follows. First we used a combination of the C-COSMO and Consumer Localism Scales proposed by Riefler, Diamantopoulos, \& Siguaw (2012) to statistically extract CCGI from an initial sample of 138 university students. Subsequently, we conducted in depth interviews with twenty Japanese CCGI and analysed

Received: November 15, $2016 \quad$ Accepted: March 16, 2017

Corresponding author: Shinichiro Terasaki, School of Humanities and Social Sciences, Faculty of Humanities and Social Sciences, Kochi University, 2-5-1 Akebono-cho, Kochi-shi, Kochi 780-8520, Japan.

E-mail: shining-t@akane.waseda.jp 
the resulting qualitative data using a grounded theory approach. The analysis revealed four antecedents to cosmopolitan consumerism (Influence of Immediate family, Personal international social networks, Education, and Personality), and three moderators (Kyoiku mama, Reaffirming national identity, and Adaptation stress) that acted as obstacles in the transition process of becoming a cosmopolitan consumer. Based on these findings we then developed a model to show the reciprocal relationships between antecedents and moderators in the acculturation process.

\section{LITERATURE REVIEW}

\subsection{Sociological approaches to cosmopolitanism}

The current boom in writing and research on cosmopolitans has coincided with the period of intensified globalization that began with the end of the Cold War in the late 1980s. For many sociologists (see for example Beck, 2006; Delanty, 2009; Szerszynski \& Urry, 2006) the development of high-speed communications technologies, the lowering of barriers towards international travel, international flows of goods and services, and the institutionalization of frameworks for the protection of universal human rights, have come together to turn the normative ideal of the cosmopolitan citizen into an observable phenomenon (Igarashi \& Saito, 2014, p. 224).

Nonetheless there is a critical strand in the literature that takes issue with such a rosy view of cosmopolitanism. Skey (2012, p. 2) for example argues that while there have been many studies of cosmopolitans, it is unclear what it is that ties together such diverse practices as "shopping for exotic foodstuffs", "showing appreciation for opposing football teams" and, in an extreme example, "sex tourism". Calhoun (2007, p. 25) also warns against the reification of an abstract ideal of cosmopolitan, arguing that cosmopolitans, although posited as transcending local solidarities, must always act within particular material contexts. Seeing cosmopolitans as free-floating citizens of the world therefore runs the risk of obscuring their reliance on local social structures, and belittles the local traditions that animate the lives of most the world's population. Indeed, scholars drawing on the work of sociologist Pierre Bourdieu (1984) have argued that cosmopolitanism, rather than being an expression of universal values, may instead be a strategy employed for status-seeking. While traits associated with cosmopolitanism have been rendered desirable in a global world, access to institutions that develop those traits is limited by socio-economic status (Igarashi \& Saito, 2014; Weenink, 2008). Thus, instead of leading to a levelling of social difference across borders, unequal access to cosmo- politan capital may in fact maintain stratification at the global level (Igarashi \& Saito, 2014, p. 234).

\subsection{Cosmopolitanism in consumer studies}

Turning to the marketing literature we see that researchers have tended to work within the assumptions of the first stream of research discussed above, focusing on the consumption habits rather than socio-economic status of an emerging cosmopolitan consumers "whose orientation transcends any particular culture or setting" (Cannon \& Yaprak, 2002, p. 229; see also Cleveland, Papadopoulos, \& Laroche, 2011b; Hannerz, 1992, p. 252; Kurasawa, 2004, p. 240). In a similar manner, Riefler and Diamantopoulos (2009, p. 415) characterize the cosmopolitan consumer as "an open-minded individual whose consumption orientation transcends any particular culture, locality or community and who appreciates diversity including trying products and services from a variety of countries". Thompson and Tambyah (1999), however, make the important point that cosmopolitan consumption should be understood as a dynamic process. Likewise, Cannon and Yaprak (2012, p. 12) have argued that cosmopolitanism be viewed as a "journey rather than a destination", with cosmopolitanism signifying "a growing under-standing, acceptance, and appreciation of the world as it is" (Cannon \& Yaprak, 2012, p. 13).

Previous investigations into the journey of cosmopolitan becoming have noted both demographic and psychographic drivers. The former relates to personal capital such as education (Cleveland, Laroche, \& Papadopoulos, 2009; Cleveland, Erdoğan, Arkkan, \& Poyraz, 2011a), multilingualism (Cleveland et al., 2011a), international social networks, and international travel (Nijssen \& Douglas, 2008). These studies have also found that gender is irrelevant as a variable (Cleveland et al., 2009; Lee, Lee, \& Lee, 2014; Riefler et al., 2012).

Regarding psychographic drivers, Cleveland et al. (2011a) regressed cosmopolitanism on the psychographic indices of Schwartz's value survey (hereafter, SVS) using Canadian and Turkish samples, and found the following antecedents: universalism, benevolence, self-direction, and stimulation of SVS-10, motivationally distinct values at individual level (Schwartz, 1992). Intellectual autonomy, affective autonomy, egalitarianism, and harmony of SVS-7, that represents shared ideas about morality, rightness, and desirability in the focal society (Schwartz, 1999), have also been clarified as drivers of cosmopolitanism. Cleveland et al. (2011a) also regressed cosmopolitanism using Hofstede's (1994) cultural indices, but other than individualism they were revealed to be mostly irrelevant to cosmopolitanism. More recently Lee et al. (2014) investigated the path to 
cosmopolitanism from normative influence (the tendency to conform to the expectation of others) and informative influence (the tendency to internalise information from others as evidence of truth) (Bearden, Netemeyer, \& Teel, 1989; Burnkrant \& Cousineau, 1975; Deutsch \& Gerard, 1955), both of which were known as interpersonal influence. Only informative influence was revealed to be significant.

As can be seen above, a handful of investigations have explored the linear relationship between cosmopolitanism and antecedents. Yet these studies have not looked into why and how antecedents link to consumer cosmopolitanism, and have not identified moderators for becoming a cosmopolitan consumer. Furthermore, the literature has not explored the reciprocal relationships between each antecedent. Providing answers to these questions for CCGI constitutes the core of this paper. The sociology literature, however, raises additional questions that may help thicken out our understanding of CCGI. If the local is always imbricated in cosmopolitanism, then how do the local and global interact in the development of cosmopolitan consumer practices? Furthermore, what is the impact of national contexts (such as that of Japan) on styles of cosmopolitan consumerism? And following the cosmopolitanism as cultural capital argument, how does cosmopolitan consumerism function as a method of differentiation and social stratification? The qualitative data produced through our interviews lends itself to investigation of these questions, and we will return to them in the subsequent discussion.

\section{METHODS}

This study used theoretical sampling to extract prospective interviewees, CCGI who were high in C-COSMO and low in Consumer Localism score (Riefler et al., 2012). CCOSMO measures cosmopolitan orientation, and it consists of the following three dimensions with four questions each: open-mindedness, diversity appreciation and consumption transcending borders. In contrast, Consumer Localism measures local orientation, and consists of a single dimension with six queries. The response format of C-COSMO and Consumer Localism is a seven-point Likert scale, $1=\mathrm{I}$ strongly disagree, $7=$ I strongly agree.

We delivered a questionnaire to 138 people who are currently undergraduate or postgraduate students in Japan, and removed 30 overseas students, thereby obtaining 108 Japanese samples. The two scales, C-COSMO and Consumer Localism, were used to divide the 108 Japanese samples into the following four groups by median split: CCGI, CCLI, Parochial consumers with a local identification, and Parochial consumers with a global identification (Cannon \& Yaprak, 2012, p. 12).
We used a median split to address some issues with previous methodologies. Riefler et al. (2012, pp. 155-156), for example, presents four types of consumer group through a cluster analysis that utilizes the categories of pure cosmopolitan, local cosmopolitan, moderately attached consumer, and alienated consumer. But while this typology is helpful for targeting purposes, the criteria by which high, moderate and low are differentiated are not clear. Furthermore, as Cannon and Yaprak (2012, pp. 11-12) point out, the status of moderately attached consumers remains ambiguous. Use of median split avoids these problems because it does not depend on a generated cluster in each empirical study.

Through the combination of C-COSMO and Consumer Localism scales, samples were categorized into the following four groups: thirty CCGI (27.8\%), thirty CCLI (27.8\%), twenty-four parochial consumers with a global identification $(22.2 \%)$, and twenty-four parochial consumers with a local identification (22.2\%). The basic statistics of each scale in our sample are as follows: C-COSMO (mean = 68.5 , median $=69$, mode $=77$, standard deviation $=9.1$, minimum score $=39$, maximum score $=84$, Cronbach's $\alpha=$ $0.86)$, Consumer Localism scale $($ mean $=34.9$, median $=$ 35.5 , mode $=36$, standard deviation $=4.9$, minimum score $=16$, maximum score $=42$, Cronbach's $\alpha=0.74)$. Confirmatory factor analysis showed satisfactory model fit $\left(\chi^{2}=\right.$ $143.23(d f=51)$; GFI = 0.97; AGFI = 0.95; NFI = 0.94 $)$, thereby supporting the stability of C-COSMO (Hair, Anderson, Babin, \& Black, 2010). Furthermore, the individual dimensions of $\mathrm{C}$-COSMO showed good internal reliability values of 0.86 for open-mindedness, 0.72 for diversity appreciation, and 0.72 for consumption transcending borders (Hair et al., 2010). The correlation coefficient between C-COSMO and Consumer Localism was 0.06 $(n s)$, and was revealed to be unrelated and independent.

Twenty out of thirty CCGI agreed to participate in interviews, and the informants were interviewed in Japanese in their home university for approximately one hour. The names of the informants were coded from G1 to G20 to ensure anonymity: "G" simply symbolizes a cosmopolitan consumer with a global identification (Table 1). The scores of C-COSMO and Consumer Localism for each interviewee are also shown in the right column of Table 1 . The sample size was consistent with other qualitative investigations into consumer cosmopolitanism, such as Thompson and Tambyah (1999) and Tambyah and Chen (2012), which explored fourteen and twelve samples respectively.

The qualitative analysis was then conducted in Japanese to explore the backgrounds of cosmopolitan consumers to understand some of the key elements involved in the constitution of this consumer group. The interview data was analysed following Strauss and Corbin's (1990) grounded 
Table 1 Profiles of twenty CCGI

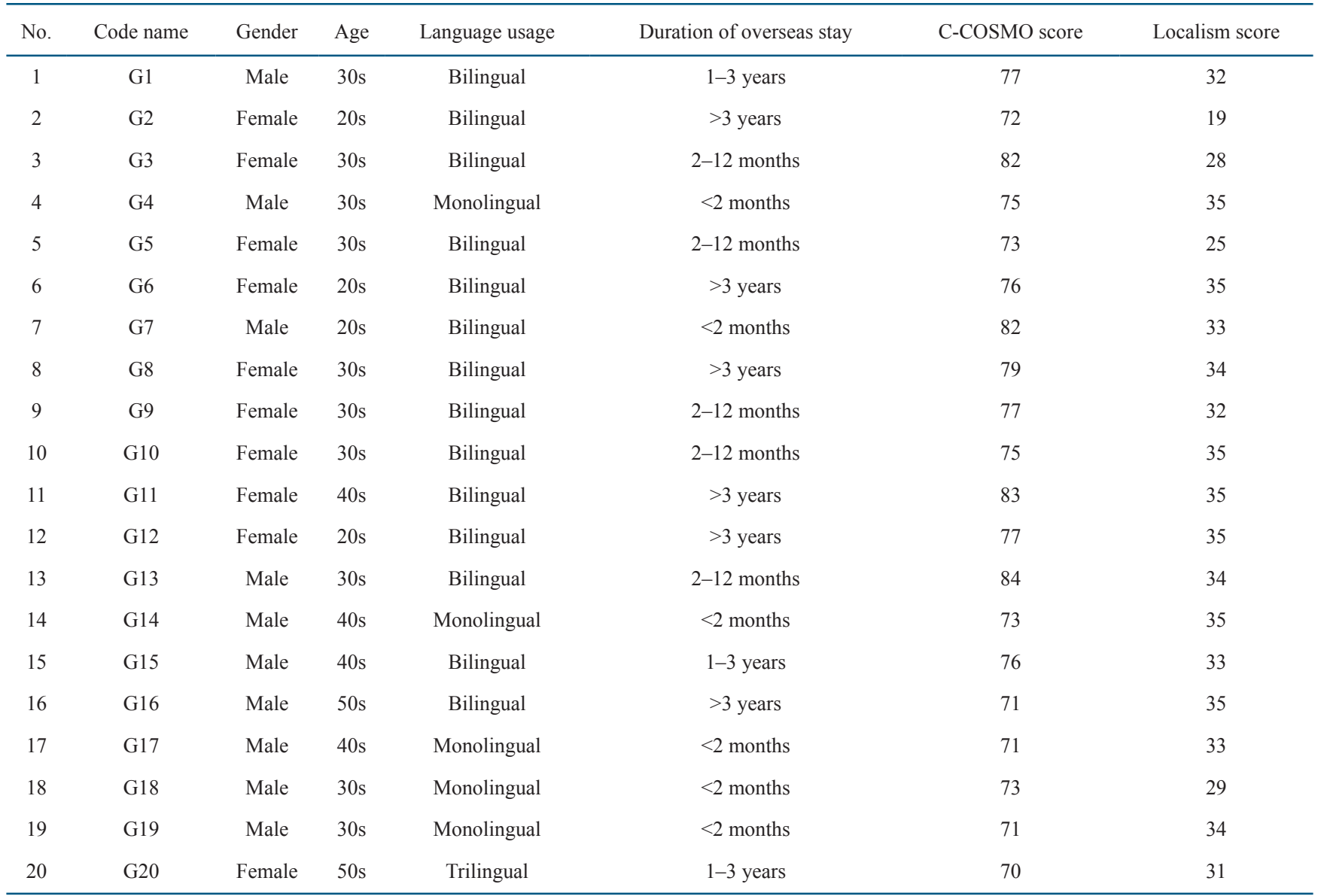

theory approach to generate well-integrated, inductive antecedents and moderators. The approach comprised three steps: open coding to form categories and subcategories, axial coding to relate categories with subcategories, and selective coding to explain causal relationships between categories. The interviews were semi-structured and initiated by a series of "ground tour" questions (McCracken, 1988) concerning the participants' personal backgrounds, interests and the circumstances in which they developed their cosmopolitan traits. As per the procedure of Thompson and Tambyah's (1999) qualitative research, all comments of both the interviewer and interviewees were recorded through a portable recorder. Verbatim transcripts from the interviews constituted our textual data and produced 400 pages of single-spaced text. The English language excerpts from the interviews that appear later in this paper were translated by the authors, who are both fluent in Japanese and English.

\section{RESULTS}

Grounded theory analysis of the qualitative data revealed the following four broad categories of antecedent character- istics associated with CCGI: (1) influence of immediate family; (2) personal international social networks; (3) education; and (4) personality. Each category was broken down into several sub-categories referring to excerpts from recorded data, which we discuss below. Here, we explain each antecedent with several subcategories, focusing on the life story of the respondents (McCracken, 1988) to help understand the reciprocal relationship between antecedents and moderators. The respondents are referred to by the code names shown in Table 1.

\subsection{Influence of immediate family}

Eleven out of twenty respondents pointed out the influence of immediate family on their cosmopolitan traits. When looked at further this category has three subcategories, influence of father, influence of mother, and pre-existing international social networks. Apart from one interviewee (G15), our respondents did not indicate the influence of siblings, probably because siblings are generally too young to proactively enculturate various cultures.

4.1.1 Influence of father. Seven respondents noted that their father's influence nurtured their cosmopolitan traits 
(G1, G2, G5, G6, G9, G10, and G20). Above all, respondents indicated that stories of their fathers' travels, business trips, and souvenirs played an important role in their enculturation (G1, G5, G9, and G20). The following excerpts illustrate this subcategory.

G1: My father traveled to various countries before I was born. He said that he had "traveled to over forty to fifty countries". After I was born too, he went on business trips to various places, gave me souvenirs and told me stories of his travels. Also, I guess when I was a child, probably in the 1980s or early 90 s, he had a condominium in the Philippines. During the summer and winter holidays, he sometimes stayed there for one or two weeks.

G9: My father frequently traveled to major countries in Europe, (North) America, and Asia for business. He went to America the most and stayed there the longest. In a roundabout sort of way, through him I was influenced by American culture. He told me stories of his travels and brought me back souvenirs, that sort of thing.

In addition, some fathers stayed abroad as expatriates for several years, and brought their families with them (G2, G6). For G2 this was a very important aspect of her enculturation: "[b]ecause my father let me join the local community (of Pennsylvania), I became naturally intimate with a different culture, and communicated with them in English" (G2). But while six respondents noted the influence of their father, ten respondents revealed that their fathers were not interested in or had no connection with overseas cultures (G3, G7, G8, G11, G12, G13, G15, G16, G17, and G18). One respondent noted the influence of his uncle who might be considered a substitute father. So, for G13 the influence of his father was marginal, whereas he was influenced by his uncle who often told the story of expatriate experience in the United States. As such, the father's influence on the development of cosmopolitan traits is a mixed picture.

4.1.2 Influence of mother. Interviewees also noted the influence of their mothers on their cosmopolitan outlook, but as with the influence of fathers the picture is mixed. When asked to reflect on the development of cosmopolitan traits, seven out of twenty interviewees noted the positive influence of their mother (G2, G3, G7, G9, G11, G13, and G20). For example:

G3: When I was a third or fourth year schoolgirl, my mother operated an independent English school. She graduated from a college of the arts, and at that time, she studied overseas. Then, she became a housewife, and started thinking about running an English school. The influence of my mother as an English teacher was significant [for the development of my cosmopolitan traits]. Due to her influence, I became interested in overseas cultures.

In general, respondents' mothers (G2, G3, G7, G9, G11, and G20) were familiar with overseas cultures. Some were teachers of English (G2, G3) or classical piano (G9), and three mothers were revealed to be fans of overseas movies and TV dramas (G9, G11, G20) and food (G2, G9). But the data also suggests that the mother's influence is not necessarily always positive. Some interviewees reported suffering excessive educational pressure from mothers (termed in Japanese Kyōiku mama, education mothers), which made them afraid of studying. Two out of twenty interviewees noted the negative influence of Kyoiku mama (G2, G8). For example:

G2: After returning from Pennsylvania, to maintain my English listening skills my mother forced me to listen to a tape of the Harry Potter Series over and over. I felt like I was becoming neurotic. Because of this experience, for a while I seriously disliked English and American culture.

The responses from G2 and G8 regarding the negative impact of their education mothers is revealing for a number of reasons. First, as noted in the discussion at the beginning of this paper, cosmopolitan theories have the tendency to gloss over the complicated interaction of the local and the global in the production of cosmopolitanism identities. But in the case of G2 and G8, we can see how Japanese orientations to education, in particular the importance of educational attainment and the importance of the child's success to the mother's sense of self-worth, manifest in ways that impact on the ability of some young Japanese to develop cosmopolitan competencies (speaking English).

It is also noteworthy that while G2's negative experience with her mother rendered her temporarily afraid of overseas cultures, she in fact recovered owing to the feeling of linguistic superiority over other Japanese classmates when compulsory English language classes started in junior high school. Therefore, consistent with the critical cosmopolitan literature (e.g., Igarashi \& Saito, 2014) we see in this example evidence of cosmopolitan traits being used by individuals as a method of differentiation, in this case through juxtaposition with the national non-English language speakers. Indeed, G2's example clearly demonstrates both cosmopolitanism as a non-linear process and cosmopolita- 
nism as a situational identity strategy activated in particular contexts. The cosmopolitan trait of being able to speak English changed from being a source of trauma ("I felt like I was becoming neurotic") to a source of status and pride. Cosmopolitanism, then, may not be a persistent state but rather an identification that is activated through demonstration of those traits associated with it; that is to say cosmopolitanism may be an instrument used for expression or self-promotion in a particular time or place, and for particular reasons (Skey, 2012, p. 7).

4.1.3 Pre-existing international social networks. Five interviewees indicated the influence of Pre-existing international social networks (Pre-ISNs) on their cosmopolitan traits (G2, G7, G8, G15, and G20). These Pre-ISNs were acquired passively rather than proactively, and mainly from the interviewees' parents (G2, G7, G8, and G20). The following quote from G8 illustrates the influence of PreISNs.

G8: My mother has a Chinese friend who used to be a Chinese teacher in Japan. [When I was a second-year junior high school student], she suggested a homestay in America to my mother and I said "Yes I'll go!" I wanted to go abroad and I wanted to spend some time away from my parents. But it wasn't like the initiative had come from me.

Also, both G2 and G8 pointed out the importance of their mothers' Pre-ISNs. "My mother continues to communicate with her overseas friends in America. The friendship has continued since she studied in America when she was an undergraduate student" (G2). Although the parents of G15 have no Pre-ISN, his elder sister has an American husband who became the Pre-ISN for G15.

G15: My older sister got married to her American boyfriend. She went to study in America for one year when she was an undergraduate student at a foreign language university. One day, after I came back from high school baseball training, she brought her American boyfriend to my house. My family was surprised very much at the sudden visit. Later, she started to live in Seattle where they held their wedding. I stayed in Seattle for around two weeks to attend the wedding, and saw his family, relatives and friends. This was when I was an undergraduate student. Since then, I went to visit my sister at least two times.

After the influence of international experience in Seattle, G15 decided to study English for one year in Kentucky, where there were few Japanese people, to broaden his horizons. It appears that when CCGI have Pre-ISNs, the acculturation period is shortened because these networks promote overseas experience. In addition, while Nijssen and Douglas (2008) and Froese, Jommersbach, \& Klautzsch (2013) found that international social networks were an antecedent of cosmopolitanism, they referred to acquired rather than inherited networks. Pre-ISNs can therefore be considered a new antecedent for consumer cosmopolitanism.

\subsection{Personal international social networks}

While Pre-ISNs refer to inherited social networks generally provided by parents, Personal international social networks (PISNs) are acquired by the interviewees through their international experience. Nine of the twenty interviewees, G5, G6, G9, G11, G12, G13, G18, G19, and G20 pointed out the influence of PISNs, which were constructed primarily through personal interaction with people overseas. Some PISNs dissolved due to geographical distance and the passage of time (G9, G12, G13, G18, G19, and G20), but a smaller group of respondents (G5, G6, and G11) maintained communication with their overseas networks through direct contact and social networking services such as Facebook. The following excerpts illustrate this subcategory:

G6: I still exchange Christmas presents with my friends in Wales [where she stayed when she was two to eight years old]. Once they came to visit me in Japan, then I went to see them in the United Kingdom again. It was long time ago though.

This sort of story comes up in other interviews: G11 also kept in contact with her English teacher by visiting him in Glasgow, and although G13 recently stopped correspondence with his Australian friends from his experience abroad as a high school student, he visited them again when he was an undergraduate student. Also, given easy access to communication technology such as social networking, it is much easier to sustain PISNs: for example G19 argued that Facebook allowed him to maintain his PISNs with Korean friends who once studied in the same university.

\subsection{Education environment \& education abroad}

A handful of studies argue for a positive correlation between educational attainment and cosmopolitanism (see Cleveland et al., 2009; Phillips \& Smith, 2008; Riefler et al., 2012; Robinson \& Zill, 1997). This category refers to the influence of education on the CCGI regardless of whether it is formal or informal, and does not necessarily 
correspond with attainment.

As discussed above, critical research into cosmopolitanism has argued that, rather than being a process of leveling of social difference across borders, cosmopolitanism may exacerbate social stratification due to unequal access to cosmopolitan cultural capital (Igarashi \& Saito, 2014, p. 234). The fact that ten out of twenty CCGI we interviewed studied at private high schools, and one had studied at boarding school in the United Kingdom, seems consistent with this argument. Specifically, our interviewees noted that there were many returnee children from abroad and foreign teachers at their private schools, which enabled them to study in a cosmopolitan environment and thus develop the competencies needed to interact with foreign cultures (Igarashi \& Saito, 2014, p. 225). At present few returnee children study at public schools even though the Japanese government does support some public schools to accommodate them (Okamura, 2011).

In addition, thirteen out of twenty interviewees had experience of education abroad especially when they were undergraduate students, and noted that acculturation was easier as they were naturally exposed to cross-cultural environments. After the experience of education abroad, five of the interviewees noted increased awareness of the importance of English (G1, G2, G8, G10, and G12), which then pushed them towards further international study. Thus, our results suggest that education environment brings a positive acculturation cycle towards students. But they also accord with studies that suggest that those with greater access to economic resources are more likely to display cosmopolitan traits.

Sports also played an important role in fostering cosmopolitan traits (G5, G8). The following excerpts illustrate the influence of sports as follows:

G5: When I was an undergraduate student, I studied abroad at Colorado University for a year. There were several students from Japan, but they found it hard to make local friends. For me, Ultimate Frisbee played a significant role in meeting people in Colorado. Since I was one of the top Ultimate Frisbee players in Japan, I joined the university team. Although there were no overseas students in the club, and my English wasn't good enough, the other team members regarded me as a competent player. Through Ultimate Frisbee, I was able to make many American friends compared to the other overseas students.

While G5 increased the number of local friends at Colorado University by playing Ultimate Frisbee, G8 communicated with various local people through tennis, badminton, and horse riding at boarding school in the United Kingdom. According to G5, she learned American ways of thinking through the sport. For instance, she noticed that American people tended not to worry about being in the public eye compared to Japanese people. As such, for these interviewees sport brings an opportunity to interact with local people, acculturating participants through communication.

\subsection{Personality}

This category refers to influence of inborn or acquired personality of the CCGI, and has three subcategories: curiosity, self-expression, and thrill seeking (stimulation). Regardless of whether inborn or acquired, personality is a critical antecedent of cosmopolitanism because to a greater or lesser extent, personality traits such as curiosity, selfexpression, and thrill seeking foster cross-cultural experience that nurtures cosmopolitan traits.

4.4.1 Curiosity. Most interviewees pointed out their curiosity regarding cross-cultural experiences. Curiosity is probably the key personality trait for CCGI, and it was found in thirteen out of twenty interviewees (G1, G2, G3, G7, G8, G9, G10, G11, G12, G13, G16, G17, G18, and G20). CCGI proactively attended various cross-cultural activities such as overseas travel, seminars on English conversation and the Bible, flat sharing with overseas students, taking part in theatrical performances and so on. The following quote from G7 illustrates this subcategory.

G7: [When I traveled in Thailand as a backpacker], I was carrying a $10 \mathrm{~kg}$ bag and my neck and shoulder got really stiff. And you know, there are many Thai massage shops on the Khaosan Road in Bangkok. So I had a massage, and it felt so good-I was really impressed. The pain was gone so quickly... And my Dad's got a pretty bad back and neck and I saw that he was always trying to do something about it... So I thought I would learn traditional Thai massage. I asked the masseuse where I could learn and they told me to go to a school in Chiangmai. Quite a long way north of Bangkok... Even so I went to Chiangmai and took a five-day massage course there, and learned basics. This when I was a second-year undergraduate student.

This case implies that cross-cultural experience arouses further curiosity for different cultures. G13's story was similar: as an undergraduate student, he went around Australia and New Zealand with overseas travelers who stayed in the same youth hostel. Through interaction with other travelers, he began to think about the cultural differences he en- 
countered, which further enhanced his curiosity. Although Nijssen and Douglas (2008) confirmed international travel as an antecedent of cosmopolitanism, CCGI are unlikely to travel overseas, at least voluntarily, without curiosity. Hence it is reasonable to regard international travel as an outcome rather than a driver of cosmopolitanism.

Indirect experience also plays an important role for arousing curiosity. For instance, G11 noted that the reason he became interested in European culture derived from interaction with friends in junior high school who were enthusiasts of foreign music. Particularly, G11 became interested in UK music, which led her to go to the United Kingdom to experience first-hand the environment in which that music was produced.

4.4.2 Self-expression. We have already touched upon cosmopolitanism and differentiation in the discussion of G2 and the influence of her kyoiku mama (education mother). In that case, the negative impact of her mother's badgering impeded G2 in acquiring cosmopolitan traits, but when it became clear that G2's English language ability gave her status at school she reevaluated the utility of being a cosmopolitan. G2's case, however, was not isolated: several interviewees (G4, G9, G12, and G16) reflected on the utility of performances of cosmopolitanism when wanting to stand out from the national crowd. For example:

G12: This applies to me now too but I've always wanted to stand out. The reason I decided to attend a local English club was that I thought "it would be really cool if I could speak English". And when I was at home and it came to decorating my room, I'd want to use English language newspapers [on the walls]. Things with English on them were cool to me.

G4: I like it when I am being fashionable, and want to feel a sense of superiority over people who aren't fashionable. This probably comes from a need to be popular with girls. And to get the girls, I need to stand out from the crowd. Seems stupid to say it out loud but suits, aftershave, and other Western things were the tools to do so.

Both G4 and G12 like to stand out conspicuously by associating themselves with Western culture. Although selfexpression did not appear among the other fifteen interviewees, we need to examine this antecedent carefully since it is clearly related to the consumer behavior of CCGI. Specifically, self-expression is associated with the concept of the "extended-self" (Belk, 1988; Schouten, 1991), which denotes the ways consumers purchase spe- cific goods or services to approach an "ideal self" (Belk, 1988; McCracken, 1990). G12 tried to reach an ideal self through English language newspapers, while G4 did so through fashionable Western goods. These examples demonstrate the importance for some CCGI of performances of cosmopolitanism in status-seeking and standing out from the crowd.

Interestingly, however, our interview data demonstrated the importance of context for the construction of ideal selves. For example, G9 wanted to stand out by recommending something new such as overseas music, movies and clothes to her friends in Japan. But when she was abroad she wanted to be more Japanese:

G9: [When I studied abroad at summer school in Boston], the teacher mentioned TOYOTA and SONY to exemplify something American. Afterwards, a German student pointed out that those brands originated from Japan, and the teacher reacted really coldly. When talking about something related to Japan, it is difficult to explain my country properly.

In this case G9 could be self-expressive only when in her home country, Japan, suggesting that products from overseas do not necessarily attract CCGI when staying abroad. We will return to these findings in the discussion section of this paper, but for the time being it is worth noting that G9's experiences suggest the path to cosmopolitanism is not as linear as the literature would suggest.

4.4.3 Stimulation. A certain need for stimulation and excitement was also found in the interview data $(\mathrm{G} 1, \mathrm{G} 3$, G7, G8, G11, G12, G16, G19, and G20). Cleveland et al. (2011a) also confirmed the relationship between stimulation (akin to hedonism, yet focusing on excitement from novel experiences) and cosmopolitanism ( $\beta=.098, t=2.81$, $p<.01$ ) by using the SVS-10 (Schwartz, 1992, 1999) scale. CCGI seek thrills to avoid ordinary life, and this orientation seems to entail cross-cultural experience. Both G11 and G20 noted that life was too easy in Japan so there was no excitement. G1 also craved the challenge of cross-cultural environments:

G1: Except for somewhat dangerous countries, I want to live overseas because it's stimulating. If I were to live in Italy for example, I'd need to learn Italian, learn the way of living, and learn their customs etc., which would be a challenge. This is the kind of thing I like [...] In fact, when I stayed in Italy as an exchange student for one semester I naturally adjusted. It wasn't difficult at all. 
In the case of G1, stimulation is probably an in-born orientation, whereas G7 was not born as a thrill-seeker. Due to his father's job, he was moved around a lot as a child, and through this experience he gained the confidence needed to plunge himself fully into new environments.

\section{DISCUSSION}

Using grounded theory to analyze data taken from interviews with twenty Japanese students identified as CCGI, we found the following four categories of CCGI traits: influence of immediate family, personal international social networks, education, and personality.

In our interviews, many CCGI noted that their cosmopolitan traits were an acquired rather than inherent orientation (G1, G2, G3, G4, G6, G8, G9, G10, G13, G15, G16, G18, G19, and G20). This being said, although G10 admitted that overseas experience accelerated the degree of cosmopolitanism, she argued that inherent personality could be a prerequisite for becoming a cosmopolitan. Indeed, G10's younger sister does not have any cosmopolitan traits, even though she and G10 received almost the same education from their parents. A similar tendency was found in G15, whose younger brother is introverted unlike G15 and his older sister. This in-born characteristic of cosmopolitanism is strongly related to the personal traits of curiosity, selfexpression, and thrill seeking (stimulation). Even though we cannot disregard the acquired components of becoming a cosmopolitan, the acculturation period for CCGI with inborn personality traits may be accelerated.

Our research demonstrated the tension between the ideal of universal openness and self-differentiation through cosmopolitan traits, and evidence of unequal access to private schools where cosmopolitan traits can be developed. We also found that many of our interviewees felt a reaffirmation of their national identities (RNI) when abroad. This tendency was found in nine interviewees (G1, G2, G3, G6, G7, G10, G12, G13, and G14), and appears to have been induced by the opportunity granted by being in a foreign country to evaluate one's own national culture at a distance. Our results show that CCGI generally experience RNI during long stays in foreign countries, especially when studying abroad. The following excerpts are illustrative:

G6: During my stay at The University of British Colombia, I felt like I wanted to spread Japanese traditional culture. When I was [in Canada] I came to really appreciate the quality of Japanese food, hospitality, and technology [...] And, apart from animation, I was also shocked by the lack of a Japanese presence in the world.
G13: When I traveled around Australia and New Zealand, I saw some people who used Japanese products such as [SONY] Walkman. This made me proud of my country even though such feelings seemed somewhat childish. At that time, Japanese cellphones were far more developed compared to overseas ones because there were no smartphones like iPhone.

Thus, while our sample comprised cosmopolitan consumers with a global orientation, such a categorization does not preclude national identification. Instead both G6 and G13's examples are indicative of the situational nature of cosmo-national identification. In the national context of the English language classroom or Thai restaurant in Japan, traits associated with cosmopolitanism (language ability, appreciation for "authentic" food and restaurants, going to supermarkets that only the locals know about, finding hidden-away temples etc.) function as a marker of difference and status. But when abroad for an extended period, those very same cosmopolitan traits may become banal; unable to signify difference and therefore unable to grant status to the cosmopolitan. In this case, there seems to be a transition away from the cosmo-global and back to the national as signifier of difference and status. As with G6, when abroad the quality of national (Japanese) food, hospitality and technology suddenly became important for her identity. Not only this, the lack of Japanese impact on the world became a source of shock, demonstrating that the experience of being a cosmopolitan abroad has for G6 brought home the reality that the cosmopolitan ideal is still very much Western (Skrbis, Kendall, \& Woodward, 2004, p. 132). We must therefore be careful not to fall into the trap of seeing cosmopolitanism (and cosmopolitan consumers) as detached from nations. Instead our findings suggest we should view cosmopolitan consumers as experimenting with forms of identification that take place within and develop out of a world of nations. Furthermore, although our data certainly accords with Cannon and Yaprak's (2012, p. 12) argument that cosmopolitanism is a "journey rather than a destination", it does caution us against seeing that journey as a linear process unfolding towards an idealized, albeit unattainable, cosmopolitan self. Experiences of being a cosmopolitan consumer in Japan, and enjoying the status such an identification affords, do not necessarily carry over to other, more international settings, and coming to an appreciation of "the world as it is" (Cannon \& Yaprak 2012, p. 13) might lead the cosmopolitan back to recognizing the importance of nations and national identity. This in turn might lead CCGI to become CCLI if they are exposed to international settings longer.

Perhaps unsurprisingly, we also found that adaptation 


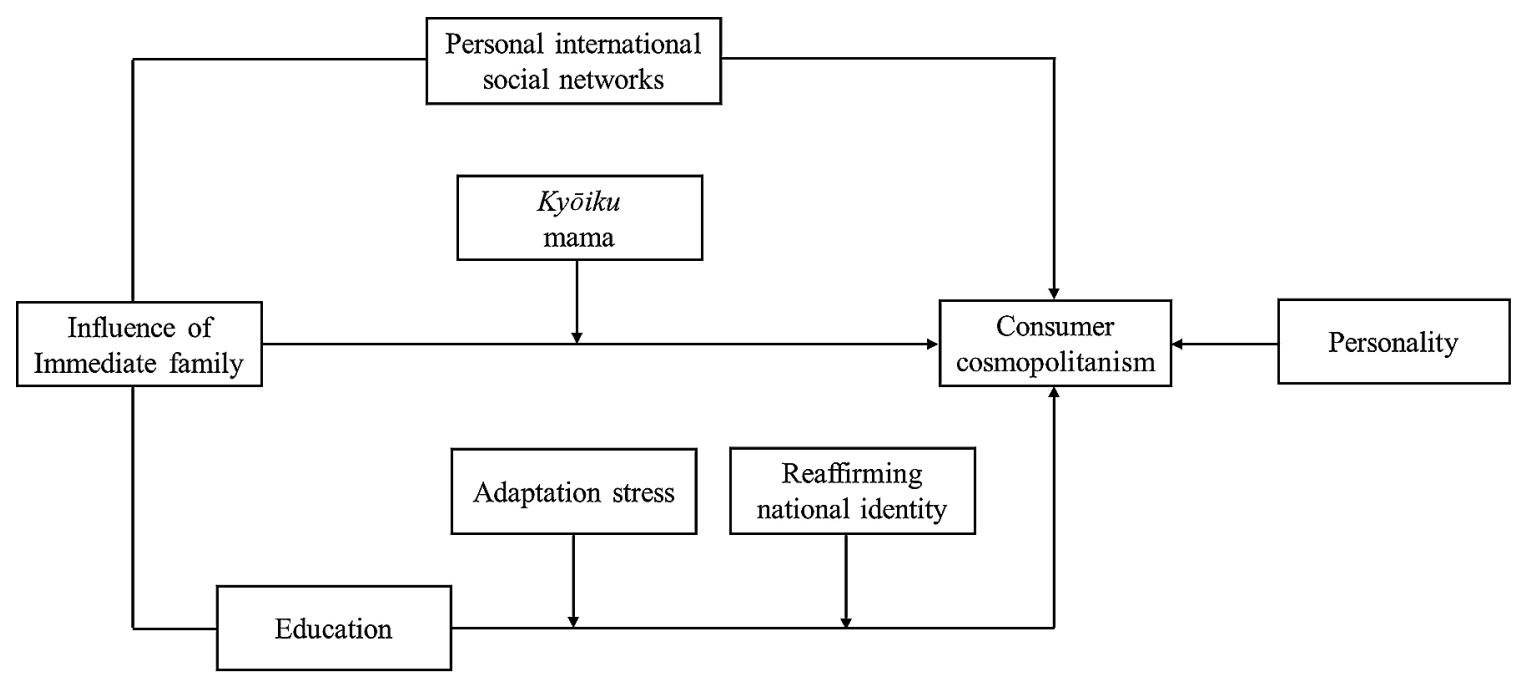

Figure 1 Antecedents and moderators of consumer cosmopolitanism.

stress acts as a moderator for acculturation (G6, G9, G11, G12, and G13). However, all five interviewees successfully overcame such stress as they stayed longer in a crosscultural environment. For instance:

G12: The first three months of working holidays [in Edinburgh] were stressful, and I really wanted to come back to Japan. First of all, I didn't know what I was supposed to do. Then, because of the low-wages from my part-time jobs in a bar and restaurant, I had trouble with money. I also lost confidence in my English. I couldn't communicate with local people, partly because of the accent.

G13: (When I went to a summer school in Melbourne), I felt uncomfortable about the habit of not taking off your shoes [before entering a house]. In particular, wearing shoes in bed! This cannot happen in Japan, where everyone takes off their shoes before entering houses.

In Figure 1 we show the relationship between antecedents and moderators in the acculturation process of becoming a cosmopolitan consumer. Figure 1 shows that the acculturation process continuously elevates consumer cosmopolitanism, and that each antecedent is not independent, but interdependent, with influence of immediate family as the starting point. Influence of immediate family is revealed to be a key antecedent to foster the other antecedents by supplying greater access to socio-economic resources.

Although some antecedents especially PISN have already been pointed out in the literature (Nijssen \& Douglas, 2008), the following four antecedents, influence of immediate family, Pre-ISNs, self-expression, and curios- ity are newly found through our research. In addition, our thick descriptive approach (Geertz, 1973), which emphasizes the importance of contextual interpretation of data, has revealed why and how antecedents link to consumer cosmopolitanism. Furthermore, several moderators that were not mentioned in existing literature were found by our analysis, such as kyoiku mama, reaffirming national identity (RNI), and adaptation stress. Kyōiku mama refers to excessive educational pressure from mothers, resulting in a temporary avoidance of overseas culture; RNI denotes a reconsideration of national identity through an emerging interest in one's native culture; while adaptation stress derives from cross-cultural experiences. These three moderators tentatively, but not permanently, slow down the speed of acculturation.

Last our data imply that consumer cosmopolitanism, as a method of extending the self through products to reach an idealized self, could be a situational identity activated in particular contexts. While our sample was identified as cosmopolitan consumers with a global orientation, such a categorization does not preclude an identification with the national, and indeed when consumer cosmopolitans are taken out of their national contexts, the data suggests that national identification may resurface.

\section{CONCLUSIONS}

Adopting a grounded theory approach, this study empirically clarified the reciprocal relationships between antecedents and moderators in the non-linear process of becoming a cosmopolitan consumer. We also specify influence of immediate family as a key antecedent in the transition process, and found cosmopolitanism as a situational identity strategy activated in particular contexts. 
To remove nation-specific differences, and to provide a basis for further cross-cultural study, we made use of a Japanese-only sample. Each antecedent comprised several subcategories, which we illustrated with excerpts from recorded data. While previous literature largely depends on deductive methods (see Nijssen \& Douglas, 2008; Riefler \& Diamantopoulos, 2009), we employed an inductive approach to empirically present antecedents. In addition, our theoretical sampling method elevated the accuracy of qualitative data collected in this research.

There are a few directions in which this research can be taken further. First, a comparison of the above findings with similar data taken from CCLI would help us better understand processes of cosmopolitan consumer identity development by enabling us to identify factors that account for the divergence in identification. Furthermore, group interviews, rather than face-to-face, could work better to get richer data. In addition, data was collected from a relatively young cohort, which meant we were unable to investigate generational differences amongst this consumer segment. Therefore, given the nonlinear nature of the CCGI journey, a life course approach (Elder, Johnson, \& Crosnoe, 2003) would help us further develop our knowledge in this important area of research.

\section{ACKNOWLEDGEMENTS}

The authors thank the editor and anonymous IJMD reviewers for their constructive feedback and suggestions during the review process, and also thank Dr. Mitsutoshi Furuya for advice on qualitative research methods. This project was supported by JSPS KAKENHI Grant Number 15K17148, FY2015 Grant Program for Promotion of International Joint Research, Waseda University.

\section{REFERENCES}

Bearden, W. O., Netemeyer, R. G., \& Teel, J. E. (1989). Measurement of consumer susceptibility to interpersonal influence. Journal of Consumer Research, 15(4), 473-481.

Beck, U. (2006). Cosmopolitan vision. Cambridge: Polity Press.

Belk, R. W. (1988). Possessions and the extended self. Journal of Consumer Research, 15, 139-168.

Bourdieu, P. (1984). Distinction: A social critique of the judgement of taste. Harvard University Press.

Burnkrant, R. E., \& Cousineau, A. (1975). Informational and normative social influence in buyer behaviour. Journal of Consumer Research, 2(3), 206-215.

Calhoun, C. (2007). Nations matter: Culture, history and the cosmopolitan dream. London: Routledge.

Cannon, H. M., \& Yaprak, A. (2002). Will the real-world citizen please stand up! The many faces of cosmopolitan consumer behavior. Journal of International Marketing, 10(4): 30-52.
Cannon, H. M., \& Yaprak, A. (2012). Cosmopolitanism as a journey: The construct and dynamics of Change. In M. Price (Ed.), Consumer cosmopolitanism in the age of globalization (pp. 3-28). NY: Business Expert Press.

Cannon, H. M., Yoon, S.-J., McGowan, L., \& Yaprak, A. (1994). In search of the global consumer. In Proceedings for the 1994 Annual Meeting of the Academy of International Business.

Cleveland, M., Erdoğan, S., Arıkan, G., \& Poyraz, T. (2011a). Cosmopolitanism, individual-level values and cultural-level values: A cross-cultural study. Journal of Business Research, 64(9), 934-943.

Cleveland, M., Laroche, M., \& Papadopoulos, N. (2009). Cosmopolitanism, consumer ethnocentrism, and materialism: An eight-country study of antecedents and outcomes. Journal of International Marketing, 17(1), 116-146.

Cleveland, M., Papadopoulos, N., \& Laroche, M. (2011b). Identity, demographics, and consumer behaviors: International market segmentation across product categories. International Marketing Review, 28(3), 244-266.

Delanty, G. (2009). The cosmopolitan imagination: The Renewal of critical social theory. Cambridge: Cambridge University Press.

Deutsch, M., \& Gerard, H. B. (1955). A study of normative and informational social influences upon individual judgment The Journal of Abnormal and Social Psychology, 51(3), 629636.

Elder, G. H. Jr., Johnson, M. K., \& Crosnoe, R. (2003). The emergence and development of life course theory. In J. T. Mortimer \& M. J. Shanahan (Eds.), Handbook of the life course (pp. 3-19), Springer US.

Froese, F. J., Jommersbach, S., \& Klautzsch, E. (2013). Cosmopolitan career choices: a cross-cultural study of job candidates' expatriation willingness. The International Journal of Human Resource Management, 24(17), 3247-3261.

Geertz, C. (1973). Thick description: Toward an interpretive theory of culture. In The interpretation of cultures: Selected essays (pp. 3-30). New York: Basic Books.

Hair, J. F., Anderson, R. E., Babin, B. J., \& Black, W. C. (2010). Multivariate data analysis: A global perspective (Vol. 7), Upper Saddle River, NJ: Pearson.

Hannerz, U. (1992). Cultural complexity: Studies in the social organization of meaning. Columbia University Press.

Hofstede, G. (1994). Value Survey Module 1994 Manual. Maastricht, Netherlands: University of Limburg.

Igarashi, H., \& Saito, H. (2014). Cosmopolitanism as cultural capital: Exploring the intersection of globalization, education and stratification. Cultural Sociology, 8(3), 222-239.

Kurasawa, F. (2004). A cosmopolitanism from below: Alternative globalization and the creation of a solidarity without bounds. European Journal of Sociology, 45(2), 233-255.

Lee, K. T., Lee, Y. I., \& Lee, R. (2014). Economic nationalism and cosmopolitanism: A study of interpersonal antecedents and differential outcomes. European Journal of Marketing, 48(5/6), 1133-1158.

McCracken, G. (1988). The long interview. Sage.

McCracken, G. (1990). Culture and consumption: New approaches to the symbolic character of consumer goods and 
activities (Vol. 1). Bloomington: Indiana University Press.

Nijssen, E. J., \&. Douglas, S. P. (2008). Consumer worldmindedness, social-mindedness, and store image. Journal of International Marketing, 16(3), 84-107.

Okamura, I. (2011). Analysis of awareness of returnee students about 'Returnee Class': With focus on the difference due to reception formation. Japanese Language Education, 42, $21-$ 30 [in Japanese].

Phillips, T., \& Smith, P. (2008). Cosmopolitan beliefs and cosmopolitan practices. Journal of Sociology, 44(4), 391-399.

Riefler, P., \& Diamantopoulos, A. (2009). Consumer cosmopolitanism: Review and replication of the CYMYC scale. Journal of Business Research, 62(4), 407-419.

Riefler, P., Diamantopoulos, A., \& Siguaw, J. A. (2012). Cosmopolitan consumers as a target group for segmentation. Journal of International Business Studies, 43(3), 285-305.

Robinson J. P., \& Zill, N. (1997). Matters of culture. American Demographics, 19, 48-52.

Schouten, J. W. (1991). Selves in transition: Symbolic consumption in personal rites of passage and identity reconstruction. Journal of Consumer Research, 17(4), 412-425.

Schwartz, S. H. (1992). Universals in the content and structure of values: Theoretical advances and empirical tests in 20 countries. Advances in Experimental Social Psychology, 25(1), 165.

Schwartz, S. H. (1999). A theory of cultural values and some implications for work. Applied Psychology, 48(1), 23-47.

Skey, M. (2012). We need to talk about cosmopolitanism: The challenge of studying openness towards other people. Cultural Sociology, 6(4), 471-487.

Skrbis, Z., Kendall, G., \& Woodward, I. (2004). Locating cosmopolitanism between humanist ideal and grounded social category. Theory, Culture \& Society, 21(6), 115-136.

Strauss, A., \& Corbin, J. (1990). Basics of qualitative research. Newbury Park, CA: SAGE.

Szerszynski, B., \& Urry, J. (2006). Visuality, mobility and the cosmopolitan: inhabiting the world from afar. The British Journal of Sociology, 57(1), 113-131.

Tambyah, S. K., \& Chen, D. (2012). Cosmopolitans go shopping: a phenomenological inquiry into how cosmopolitans relate to global and local brands. In M. Prince (Ed.). Consumer cosmopolitanism in the age of globalization. NY: Business Expert Press.

Terasaki, S. (2016). Cosmopolitan consumers: Research overview and research opportunities. Journal of International Business Research, 15(1), 32-45.

Thompson, C. J., \& Tambyah, S. K. (1999). Trying to be cosmopolitan. Journal of Consumer Research, 26(3), 214-241.

Weenink, D. (2008). Cosmopolitanism as a form of capital parents preparing their children for a globalizing world. Sociology, 42(6), 1089-1106.

Zeugner-Roth, K. P., Zabkar, V., \& Diamantopoulos, A. (2015). Consumer ethnocentrism, national identity, and consumer cosmopolitanism as drivers of consumer behavior: A social identity theory perspective. Journal of International Marketing, 23(2), 25-54. 


\section{Appendix. Scale Items}

\section{C-COSMO}

\begin{tabular}{|c|c|c|}
\hline Items & Factor loading & Cronbach's $\alpha$ \\
\hline \multicolumn{3}{|l|}{ Open-mindedness } \\
\hline When traveling, I make a conscious effort to get in touch with the local culture and traditions. & 0.60 & 0.86 \\
\hline I like having the opportunity to meet people from many different countries. & 0.93 & \\
\hline I like to have contact with people from different cultures. & 0.85 & \\
\hline I have got a real interest in other countries. & 0.75 & \\
\hline \multicolumn{3}{|l|}{ Diversity appreciation } \\
\hline Having access to products coming from many different countries is valuable to me. & 0.68 & 0.72 \\
\hline The availability of foreign products in the domestic market provides valuable diversity. & 0.50 & \\
\hline I enjoy being offered a wide range of products coming from various countries. & 0.86 & \\
\hline Always buying the same local products becomes boring over time. & 0.40 & \\
\hline \multicolumn{3}{|l|}{ Consumption transcending borders } \\
\hline I like watching movies from different countries. & 0.53 & 0.72 \\
\hline I like listening to music of other cultures. & 0.76 & \\
\hline I like trying original dishes from other countries. & 0.56 & \\
\hline I like trying out things that are consumed elsewhere in the world. & 0.69 & \\
\hline
\end{tabular}

\section{Consumer Localism}

Items

News from my home country interests me a lot.

I pay much attention to local news.

I appreciate the importance of following traditions.

I like having traditional dishes from my home country.

I have close bonds to the people in my home country.

I like being in my home country.
Factor loading Cronbach's $\alpha$

$\begin{array}{ll}0.82 & 0.74 \\ 0.53 & \\ 0.46 & \\ 0.43 & \\ 0.74 & \\ 0.53 & \end{array}$

